\title{
USING OF BINOMINAL METHOD FOR THE PURPOSE OF DETERMINATION OF CONFIDENCE INTERVALS FOR PREDICTION OF INVASIVE DUCTAL BREAST CARCINOMA METASTASES
}

\author{
Alexandr Lazaruk \\ Department of Pathological Anatomy \\ Higher State Educational Establishment of Ukraine \\ "Bukovinian State Medical University» \\ 137 Golovna str., Chernivtsy, Ukraine, 58005 \\ lazarukov@ukr.net \\ Igor Davydenko \\ Department of Pathological Anatomy \\ Higher State Educational Establishment of Ukraine \\ «Bukovinian State Medical University» \\ 137 Golovna str., Chernivtsy, Ukraine, 58005 \\ pathomorphology@bsmu.edu.ua
}

\begin{abstract}
The study was performed using surgical and biopsy material based on histopathological study, which was conducted at the Chernivtsy Regional Clinical Oncology Centre. In the cases of verified diagnosis of ductal breast carcinoma was studied the size of the primary tumour node and metastasis in lymphogenous features of regional lymph node according to classification system TNM. All cases were divided by categories T and N. Using statistical data was conducted the analysis in patients of verified diagnosis of ductal breast carcinoma in Chernivtsy region. We determined the features of metastasis to regional lymph nodes under according to the classification pTNM and confidence intervals calculated according to percent binomial method with $\mathrm{p}=0.05$. After receiving the results the data were compared to predict metastasis. Using statistical data were conducted the analysis in women of Chernivtsi region with verified diagnosis of ductal breast cancer. We determined the features of metastasis classification according pTNM and confidence intervals of percent according to binominal method with $\mathrm{p}=0.05$. All observations of histopathological conclusions were conducted on the basis of Chernivtsy Regional Clinical Oncology Centre.
\end{abstract}

Keywords: ductal breast carcinoma, binominal method, predicting metastasis.

\section{Introduction}

Breast carcinoma ranks first in the world like a malignant cancer in women (Fig. 1).

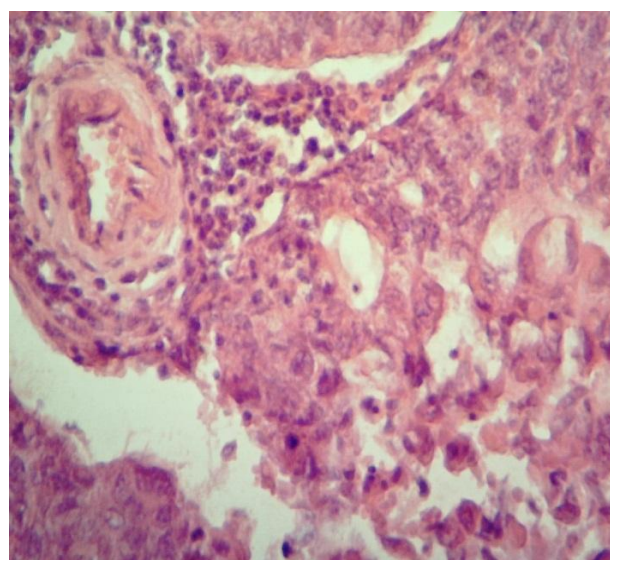

Fig. 1. Invasive ductal breast cancer 
Malignancy of the disease is caused by the emergence of metastases. Metastases - secondary tumour focus in tissues arising from the spread of the tumour in the patient's body (Fig. 2, 3).

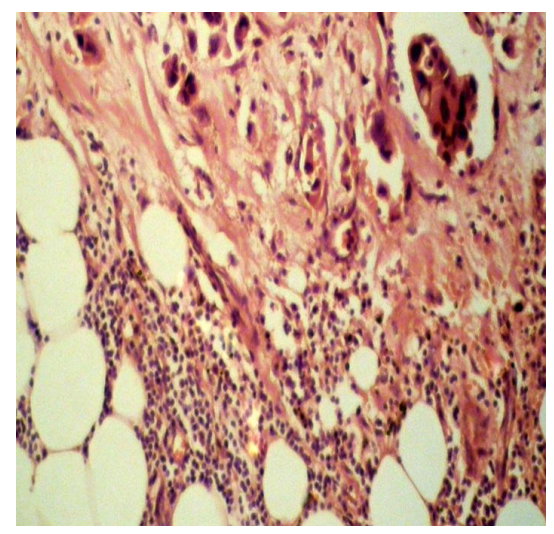

Fig. 2. Metastasis breast cancer in an axillary lymph nodes

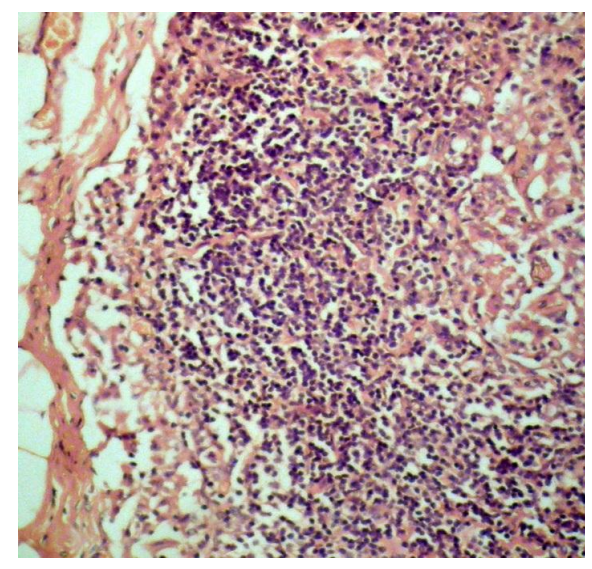

Fig. 3. Metastasis breast cancer in an axillary lymph nodes

The problem of the emergence of metastases more significant than the primary tumour [1, 2]. If the primary tumour can be treated surgically, it is much more difficult, and often impossible to identify and remove multiple metastases [2-4]. The presence of metastases immediately worsens the prognosis of life and treatment of tumours. An important task is to prevent metastasis and to detect cancer at an early stage. This kind of research are essential because the occurrence of secondary tumours in the later stages of the disease are the leading causes of death in sick women [5]. Many scientists study the possibility of appearance metastasis for a long time. Research methods of forecasting the emergence of metastases are interesting because in solving problem are arising chances to prevent undesirable complications of tumour $[5,6]$.

One of the priority tasks of predicting ductal breast carcinoma metastasis is the use of methods that are based on an assessment of the primary node size (based on system TNM). In particular, one could calculate the overall rate at a certain contingent of women, incidence of certain types of metastases and to evaluate the prognosis of their frequency by using one of the existing statistical methods [7-10]. Today, the best method of frequency prediction is calculating binominal confidence intervals percent. This method uses a complex mathematical algorithm, but it is the most mathematically justified among other methods-analogues (for instance, "interval Wilson's" or "interval Argesti-Coull»), and therefore is also called "Exact method" and allows you calculate confidence intervals taking into account the frequency of asymmetric features, especially when analyzed small or great frequency. It should be noted that due to the asymmetrical frequency characteristics it would be wrong to use the previously popular method of calculation of confidence intervals by applying a symmetric frequency error [10-12]. So, to predict the frequency of ductal 
breast cancer metastasis by the tumour size according to the TNM system is used binominal method of calculating percent confidence intervals (frequencies).

\section{Aim of the research}

To predict metastasis of invasive ductal breast carcinoma by the tumour size (using TNM system) in women of Chernivtsi region by using the binominal method for determining percent confidence intervals (frequency).

\section{Research materials and methods}

Study sample included 162 cases of invasive ductal breast carcinoma. Research was conducted in the age group of 27 to 75 years. The average age was 59 years. It was diagnosed on the basis of Chernivtsi Regional Clinical Oncology Center in 2014-2015. Additional researches were conducted at the Department of Pathology Anatomy of Higher State Educational Establishment of Ukraine «Bukovinian State Medical University».

Operational and biopsy material was sent to research to the department of pathologists, fixed in buffered phosphate buffer formalin. On the next day was selected material that is most suitable for further research: interested tumour tissue on both sides of the border of dense tumour site [13]. After fixation and dehydration in ascending alcohol batteries specimens were stained with hematoxylin-eosin. According to histopathological techniques were performed micropreparations microscopy, was established histopathological diagnosis and coding according to the international classification of TNM [13-16]. The required results were analyzed by statistical methods. Retrospective analysis and grouping of the results of the study was conducted. All results are divided by categories according to classification TNM. Conducted calculation and comparison of the results for different variations, calculated percent confidence interval in accordance to binominal method with $p=0.05$. All calculated results are analyzed and criteria for predicting within a confidence interval were established.

Using computer software equipment for statistical calculations - PAST 3.11 (O. Hammer, 2016, freeware), according to the binominal method were counted the limits for percent confidence interval at $\mathrm{p}=0.05[17-19]$.

\section{Research results}

Study sample included 162 cases of invasive ductal breast carcinoma. It was diagnosed on the basis of Chernivtsi Regional Clinical Oncology Center in 2014-2015. Additional researches were conducted at the Department of Pathology Anatomy of Higher State Educational Establishment of Ukraine «Bukovinian State Medical University».

To predict metastasis of invasive ductal breast carcinoma in women of Chernivtsi region were used categories of classification pTNM with existing cases of verified diagnosis of invasive ductal breast carcinoma. The results were divided on morphological characteristics. In the basis of this classification laid morphological characteristics including size of the primary tumour and spread $\mathrm{T}_{1}-\mathrm{T}_{4 \mathrm{c}}$. We paid attention to the size of the primary tumour and metastasis features $\mathrm{N}_{0-3}$ (Table 1).

Categories without any disease observation were not shown in the Table 1. In determining the confidence interval in these groups the result was identical, that's why for the prediction it was used only as a guide. To the test categories, which did not detect any disease observation, belong $\left(\mathrm{T}_{1 \mathrm{a}} \mathrm{N}_{0}, \mathrm{~T}_{1 \mathrm{a}} \mathrm{N}_{1}, \mathrm{~T}_{1 \mathrm{a}} \mathrm{N}_{2}, \mathrm{~T}_{1 \mathrm{a}} \mathrm{N}_{3}, \mathrm{~T}_{1 \mathrm{~b}} \mathrm{~N}_{2}, \mathrm{~T}_{1 \mathrm{~b}} \mathrm{~N}_{3}, \mathrm{~T}_{3} \mathrm{~N}_{2}, \mathrm{~T}_{4 \mathrm{a}} \mathrm{N}_{0}, \mathrm{~T}_{4 \mathrm{a}} \mathrm{N}_{1}, \mathrm{~T}_{4 \mathrm{a}} \mathrm{N}_{1 \mathrm{a}}, \mathrm{T}_{4 \mathrm{a}} \mathrm{N}_{2}, \mathrm{~T}_{4 \mathrm{a}} \mathrm{N}_{3}, \mathrm{~T}_{4 \mathrm{c}} \mathrm{N}_{1}, \mathrm{~T}_{4 \mathrm{c}} \mathrm{N}_{2}, \mathrm{~T}_{4 \mathrm{c}} \mathrm{N}_{3}\right)$, thus percentage was $0 \%$, and $\mathrm{CL}=0-2,25 \%$.

In groups with verified diagnosis of ductal breast carcinoma grouped by pTNM to reduce subvariations by subcategories $\mathrm{N}_{1-3 \text { (a-c) }}$ restricted $\mathrm{N}_{1-3}$ to simplify the calculation of results and increase visibility of research.

In observation of categories $M$ (hematogenous metastases) was not get a single case, thus all conclusions we studied encrypted as $\mathrm{M}_{\mathrm{x}}$. At this stage of research any information about this category was not used. 
Table 1

Analysis of occurrence of ductal breast carcinoma metastasis in percentage and calculation limits of the confidence interval for the total number of cases in accordance with binominal method at $\mathrm{p}=0,05$

\begin{tabular}{|c|c|c|c|c|c|}
\hline Groups & $\mathbf{N}_{0}$ & Altogether $\mathbf{N}_{1}+\mathbf{N}_{2}+\mathbf{N}_{3}$ & $\mathbf{N}_{1}$ & $\mathbf{N}_{2}$ & $\mathbf{N}_{3}$ \\
\hline $\mathrm{T}_{1 \mathrm{~b}}$ & $\begin{array}{c}3(1,85 \%) \\
\mathrm{CL}=0,38-5,32 \%\end{array}$ & $\begin{array}{c}1(0,62 \%) \\
C L=0,15-3,39 \%\end{array}$ & $\begin{array}{c}1(0,62 \%) \\
C L=0,15-3,39 \%\end{array}$ & $\begin{array}{c}0 \% \\
C L=0-2,25 \%\end{array}$ & $\begin{array}{c}0 \% \\
C L=0-2,25 \%\end{array}$ \\
\hline $\mathrm{T}_{1 \mathrm{c}}$ & $\begin{array}{c}8(4,93 \%) \\
\mathrm{CL}=2,16-9,49 \%\end{array}$ & $\begin{array}{c}16(9,88) \% \\
C L=5,75-15,54 \%\end{array}$ & $\begin{array}{c}10(6,17 \%) \\
C L=3,00-11,06 \%\end{array}$ & $\begin{array}{c}2(1,23 \%) \\
\mathrm{CL}=0,15-4,39 \%\end{array}$ & $\begin{array}{c}4(2,64 \%) \\
\mathrm{CL}=0,68-6,20 \%\end{array}$ \\
\hline $\mathrm{T}_{2}$ & $\begin{array}{c}49(30,25 \%) \\
\mathrm{CL}=23,29-37,95 \%\end{array}$ & $\begin{array}{c}67(41,36 \%) \\
C L=33,69-49,35 \%\end{array}$ & $\begin{array}{c}29(17,90 \%) \\
\mathrm{CL}=12,33-24,69 \%\end{array}$ & $\begin{array}{c}15(9,26 \%) \\
C L=5,28-14,81 \%\end{array}$ & $\begin{array}{c}23(14,20 \%) \\
C L=9,22-20,54 \%\end{array}$ \\
\hline $\mathrm{T}_{3}$ & $\begin{array}{c}2(1,23 \%) \\
\mathrm{CL}=0,15-4,39 \%\end{array}$ & $\begin{array}{c}2(1,23 \%) \\
\mathrm{CL}=0,15-4,39 \%\end{array}$ & $\begin{array}{c}1(0,62 \%) \\
C L=0,15-3,39 \%\end{array}$ & $\begin{array}{c}0 \% \\
C L=0-2,25 \%\end{array}$ & $\begin{array}{c}1(0,62 \% 4) \\
C L=0,15-3,39 \%\end{array}$ \\
\hline $\mathrm{T}_{4 \mathrm{~b}}$ & $\begin{array}{c}2(1,23 \%) \\
C L=0,15-4,39 \%\end{array}$ & $\begin{array}{c}11(6,79 \%) \\
C L=3,44-11,82 \%\end{array}$ & $\begin{array}{c}6(3,70 \%) \\
C L=1,37-7,88 \%\end{array}$ & $\begin{array}{c}1(0,62 \%) \\
C L=0,15-3,39 \%\end{array}$ & $\begin{array}{c}4(2,46 \%) \\
\mathrm{CL}=0,68-6,20 \%\end{array}$ \\
\hline $\mathrm{T}_{4 \mathrm{c}}$ & $\begin{array}{c}10,62 \% \\
C L=0,15-3,39 \%\end{array}$ & $\begin{array}{c}0 \% \\
C L=0-2,25 \%\end{array}$ & $\begin{array}{c}0 \% \\
\mathrm{CL}=0-2,25 \%\end{array}$ & $\begin{array}{c}0 \% \\
C L=0-2,25 \%\end{array}$ & $\begin{array}{c}0 \% \\
C L=0-2,25 \%\end{array}$ \\
\hline $\begin{array}{l}\text { Altogether } \\
\text { (regardless } \\
\text { of tumour } \\
\text { size) }\end{array}$ & $\begin{array}{c}65(40,12 \%) \\
\mathrm{CL}=32,51-48,10 \%\end{array}$ & $\begin{array}{c}97(59,88 \%) \\
\mathrm{CL}=51,90-67,49 \%\end{array}$ & $\begin{array}{c}47(29,01 \%) \\
\mathrm{CL}=22,16-36,65 \%\end{array}$ & $\begin{array}{c}18(11,11 \%) \\
C L=6,72-16,99 \%\end{array}$ & $\begin{array}{c}32(19,75 \%) \\
C L=13,92-26,73 \%\end{array}$ \\
\hline
\end{tabular}

\section{Discussion of the research results}

All data are summarized in Table 1. There were no cases with $\mathrm{T}_{1 \mathrm{a}}$ and because of this groups and their combination without a confirmed diagnosis it is not necessary to cover in the table, thus a result of determining the confidence interval will be identical for all.

In the first column of the table is the group $\mathrm{T}_{1 \mathrm{~b}}$ - total number of cases was 4 persons $(2.46 \%)$. Category $\mathrm{N}_{0}-3$ cases of the disease $(1.85 \%)$, the confidence interval for this group $\mathrm{CL}=0,38-5,32 \%$. Category $\mathrm{N}_{1 \mathrm{a}}-1$ case $(0.62 \%), \mathrm{CL}=0,15-3,39 \% . \mathrm{N}_{2}, \mathrm{~N}_{3}$ categories were not observed $-0 \%$, limits the likely occurrence of metastases within $\mathrm{CL}=0-2,25 \%$. Totally $\mathrm{N}_{1}+\mathrm{N}_{2}+\mathrm{N}_{3}-1$ case $(0,62 \%)$, $\mathrm{CL}=0,15-3,39 \%$.

The number of cases in combination with the category $\mathrm{T}_{1 \mathrm{c}} \mathrm{N}$ was $24(14.81 \%)$ totally, including $\mathrm{N}_{0}-8$ observations $(4,93 \%) \mathrm{CL}=2,16-9,49 \% ; \mathrm{N}_{1}-10$ observations $(6,17 \%), \mathrm{CL}=3,00-11,06 \%$; $\mathrm{N}_{2}-2$ observations $(1,23 \%), \mathrm{CL}=0,15-4,39 \% ; \mathrm{N}_{3}-4$ observations $(2,64 \%), \mathrm{CL}=0,68-6,20 \%$. Totally $\mathrm{N}_{1}+\mathrm{N}_{2}+\mathrm{N}_{3}-16$ cases.

Group of $\mathrm{T}_{2}$ category is the most numerous, total number of observations is 116 (71.61\%). Confidence interval $\mathrm{CL}=64,00-78,40 \%$. The group $\mathrm{N}_{0}$ got 49 observations $(30,25 \%), \mathrm{CL}=23,29-37,95 \%$; $\mathrm{N}_{1}$ category - 29 observations (17,90\%), $\mathrm{CL}=12,33-24,69 \% ; \mathrm{N}_{2}$ category - 15 observations $(9.26 \%)$ totally, within the confidence interval 5,28-14,81\%; $\mathrm{N}_{3}-23$ observations (14,20\%), CL=9,22-20,54\%. Totally $\mathrm{N}_{1}+\mathrm{N}_{2}+\mathrm{N}_{3}-67$ observations (41.4\%).

In combination of categories $\mathrm{T}_{3} \mathrm{~N}-4$ observations $(2.46 \%)$ totally, $\mathrm{CL}=0,68-6,20 \%$; $\mathrm{N}_{0}$ category -2 observations $(1.23 \%)$, confidence interval CL within $0,15-4,39 \%$. $\mathrm{N}_{1}$ category 1 observation $(0,62 \%), C L=0,15-3,39 \% ; \mathrm{N}_{2}$ - there was no single case $(0 \%), \mathrm{CL}=0-2,25 \% ; \mathrm{N}_{3}-$ 1 observation $(0,62 \%), C L=0,15-3,39 \%$. Totally $\mathrm{N}_{1}+\mathrm{N}_{2}+\mathrm{N}_{3}-2$ observations $(1,23 \%), \mathrm{CL}=0,15-4,39 \%$.

The combination of categories $\mathrm{T}_{4 \mathrm{~b}} \mathrm{~N}$ consists of 13 observations $(8,03 \%), \mathrm{CL}=4,34-10,33 \%$. Category $\mathrm{N}_{0}-2$ cases $(1,23 \%), \mathrm{CL}=0,15-4,39 \%$; $\mathrm{N}_{1}-6$ observations $(3,70 \%), \mathrm{CL}=1,37-7,88 \%$; 
$\mathrm{N}_{2}-1$ observation $(0,62 \%), \mathrm{CL}=0,15-3,39 \% ; \mathrm{N}_{3}-4$ observations $(2,46 \%), \mathrm{CL}=0,68-6,20 \%$. Totally $\mathrm{N}_{1}+\mathrm{N}_{2}+\mathrm{N}_{3}-11$ observations $(8,02 \%), \mathrm{CL}=3,44-11,82 \%$.

In combination of categories $\mathrm{T}_{4 \mathrm{c}} \mathrm{N}-1$ observation which is $0,62 \%$ in the subcategory $\mathrm{T}_{4 \mathrm{c}} \mathrm{N}_{0}$, confidence interval $\mathrm{CL}=0,15-3,39 \%$. In categories $\mathrm{N}_{1}, \mathrm{~N}_{2}, \mathrm{~N}_{3}$ not a single observation was observed $(0 \%), C L=0-2,25 \%$.

Among the 162 observations included in the research group there were 65 cases of no metastasis, which is $40,12 \%$. The group with metastasis carried 97 observations $(59,88 \%)$. In total, the number of cases in the $\mathrm{N}_{1}$ category is $47(29.01 \%) ; \mathrm{N}_{2}-18$ observations (11,11\%); $\mathrm{N}_{3}-32(19,75 \%)$.

Prediction of the tumour metastasis using binominal method for the purpose of determination of confidence intervals is rather valuable and reliable. In categories that did not get any observation (in the ratio of $0 \%$ ) using this method was found that the risk of metastasis varies from 0 to $2.25 \%$. This makes it possible to use these results as a prognostic significance. Other techniques didn't show such results in groups with missing observations. By the number of cases and the emergence of metastases over $71 \%$ of women in category $\mathrm{T}_{2}$ are at high risk for tumour metastasis.

This method allows calculate confidence intervals based on the features asymmetric frequency, especially when analyzed small or great frequency. This statistical method can be used in combination with further histopathological studies or evaluation.

\section{Conclusions}

1. After comparison of results in categories and statistical processing was revealed that a group of undetected metastasis by binominal method of calculation of confidence intervals risk of metastases ranges from 0 to $2.25 \%$. In our study, these groups are with combination of categories: $\mathrm{T}_{1 \mathrm{a}} \mathrm{N}_{0}, \mathrm{~T}_{1 \mathrm{a}} \mathrm{N}_{1}, \mathrm{~T}_{1 \mathrm{a}} \mathrm{N}_{2}, \mathrm{~T}_{1 \mathrm{a}} \mathrm{N}_{3}, \mathrm{~T}_{1 \mathrm{~b}} \mathrm{~N}_{2}, \mathrm{~T}_{1 \mathrm{~b}} \mathrm{~N}_{3}, \mathrm{~T}_{3} \mathrm{~N}_{2}, \mathrm{~T}_{4 \mathrm{a}} \mathrm{N}_{0}, \mathrm{~T}_{4 \mathrm{a}} \mathrm{N}_{1}, \mathrm{~T}_{4 \mathrm{a}} \mathrm{N}_{1 \mathrm{a}}, \mathrm{T}_{4 \mathrm{a}} \mathrm{N}_{2}, \mathrm{~T}_{4 \mathrm{a}} \mathrm{N}_{3}, \mathrm{~T}_{4 \mathrm{c}} \mathrm{N}_{1}, \mathrm{~T}_{4 \mathrm{c}} \mathrm{N}_{2}, \mathrm{~T}_{4 \mathrm{c}} \mathrm{N}_{3}$.

2. Using counting limits of confidence intervals for the total number of cases in categories of classification pTNM indicates the probability of appearance of disease complications in the form of metastases. And, certainly, can be used for predicting metastasis of ductal breast carcinoma.

\section{References}

[1] Shapochka, D. O., Zalyetok, S. P., Hnydyuk, M. I. (2013). Molecular biological characteristics of breast cancer. Clinical Oncology, 2 (10), 138-142.

[2] Sobin, L., Gospodarowicz, M., Wittekind, Ch. (Eds.) (2009). TNM Classification of Malignant Tumours. Seventh edition. WileyBlackwell, 328.

[3] Lazaruk, A. V., Davydenko, I. (2014). Frequency of analysis ductal breast cancer according to the TNM classification in the Chernivtsi regional clinical oncology center at 2009-2013. Clinical and Experimental Pathology, XIII (2), 79-82.

[4] Schurov, N. F., Paschenko, S. N., Voloshin, N. N. (2013). Clinical morphological characteristics of the tumour stroma in a patients with breast cancer. Zaporizhia state medical university. Oncology, 15 (4), 85-91.

[5] Adams, S., Gray, R. J., Demaria, S., Goldstein, L., Perez, E. A., Shulman, L. N. et. al (2014). Prognostic Value of Tumor-Infiltrating Lymphocytes in Triple-Negative Breast Cancers From Two Phase III Randomized Adjuvant Breast Cancer Trials: ECOG 2197 and ECOG 1199. Journal of Clinical Oncology, 32 (27), 2959-2966. doi: 10.1200/jco.2013.55.0491

[6] Boroday, N. V., Lukyanova, N. Y. (2007). Hereditary breast cancer: clinical, morphological and biological characteristics. Oncology, 9 (2), 105-109.

[7] Anitei, M.-G., Zeitoun, G., Mlecnik, B., Marliot, F., Haicheur, N., Todosi, A.-M. et. al (2014). Prognostic and Predictive Values of the Immunoscore in Patients with Rectal Cancer. Clinical Cancer Research, 20 (7), 1891-1899. doi: 10.1158/1078-0432.ccr-13-2830

[8] Choi, C. H., Kang, H., Kim, W. Y., Kim, T.-J., Lee, J.-W., Huh, S. J. et. al (2008). Prognostic Value of Baseline Lymphocyte Count in Cervical Carcinoma Treated With Concurrent Chemoradiation. International Journal of Radiation Oncology*Biology*Physics, 71 (1), 199-204. doi: 10.1016/j.ijrobp.2007.09.024

[9] Coleman, M. P., Quaresma, M., Berrino, F., Lutz, J.-M., De Angelis, R., Capocaccia, R. et. al (2008). Cancer survival in five continents: a worldwide population-based study (CONCORD). The Lancet Oncology, 9 (8), 730-756. doi: 10.1016/s1470-2045(08)70179-7 
[10] Dabbs, D. J. (2010). Diagnostic immunohistochemistry: theranostic and genomic applications. Philadelphia: Saunders Elsevier Science, 941.

[11] Ferlay, J., Shin, H.-R., Bray, F., Forman, D., Mathers, C., Parkin, D. M. (2010). Estimates of worldwide burden of cancer in 2008: GLOBOCAN 2008. International Journal of Cancer, 127 (12), 2893-2917. doi: $10.1002 / \mathrm{ijc} .25516$

[12] Goldhirsch, A., Wood, W. C., Coates, A. S., Gelber, R. D., Thurlimann, B., Senn, H.-J. (2011). Strategies for subtypes-dealing with the diversity of breast cancer: highlights of the St Gallen International Expert Consensus on the Primary Therapy of Early Breast Cancer 2011. Annals of Oncology, 22 (8), 1736-1747. doi: 10.1093/annonc/mdr304

[13] Gos, M., Miłoszewska, J., Przybyszewska, M. (2009). Epithelial-mesenchymal transition in cancer progression. Postepy Biochem, 55 (2), 121-128.

[14] Hugo, H., Ackland, M. L., Blick, T., Lawrence, M. G., Clements, J. A., Williams, E. D., Thompson, E. W. (2007). Epithelial-mesenchymal and mesenchymal-epithelial transitions in carcinoma progression. Journal of Cellular Physiology, 213 (2), 374-383. doi: 10.1002/jcp.21223

[15] Loi, S., Michiels, S., Salgado, R., Sirtaine, N., Jose, V., Fumagalli, D. et. al (2014). Tumor infiltrating lymphocytes are prognostic in triple negative breast cancer and predictive for trastuzumab benefit in early breast cancer: results from the FinHER trial. Annals of Oncology, 25 (8), 1544-1550. doi: 10.1093/annonc/mdu112

[16] Mohammed, Z. M., Going, J. J., Edwards, J., Elsberger, B., Doughty, J. C., McMillan, D. C. (2012). The relationship between components of tumour inflammatory cell infiltrate and clinicopathological factors and survival in patients with primary operable invasive ductal breast cancer. British Journal of Cancer, 107 (5), 864-873. doi: 10.1038/bjc.2012.347

[17] Park, S. Y., Gönen, M., Kim, H. J., Michor, F., Polyak, K. (2010). Cellular and genetic diversity in the progression of in situ human breast carcinomas to an invasive phenotype. Journal of Clinical Investigation, 120 (2), 636-644. doi: 10.1172/jci40724

[18] Tot, T. (2014). Breast Cancer Subgross Morphological Parameters and Their Relation to Molecular Phenotypes and Prognosis. The Journal of OncoPathology, 2 (4), 69-76. doi: 10.13032/tjop.2052-5931.100106

[19] Smolanka, I. I., Sklar, S. Y., Dosenko, I. I. (2009). Prevention and early diagnosis of breast cancer. SI "National Cancer Institute of Medical Sciences of Ukraine" Female Doctor, 5, 40-45. 